\title{
Recovery of Adrenocortical Function during Long-term Treatment with Corticosteriods
}

\author{
L. WESTERHOF, M. J. vaN DITMARS, P. J. DER KINDEREN, J. H. H. THIJSSEN, F. SCHWARZ
}

British Medical fournal, 1972, 2, 195-197

\section{Summary}

The recovery of adrenocortical function during long-term corticosteroid treatment in a group of patients with asthmatic bronchitis was compared with that in a group of patients with sarcoidosis. At corresponding dosages of prednisone basal adrenocortical function as well as adrenocortical response to tetracosactrin stimulation was higher in the asthma patients than in those with sarcoidosis.

The rate of recovery of adrenocortical function seems mainly to be determined by the dosage of corticosteroids during the initial stages of treatment rather than by the nature of the disease.

\section{Introduction}

In a previous paper (Westerhof et al., 1970) we reported on adrenocortical recovery during slow withdrawal of corticosteroid treatment, with an initial dosage of $40 \mathrm{mg}$ of prednisone daily, in a homogeneous group of patients suffering from sarcoidosis. Another 18 patients with asthmatic bronchitis have been studied who had been treated for a comparable period of time with prednisone but who had not received doses exceeding $15 \mathrm{mg}$. At corresponding levels of prednisone dosage all values recorded in the latter group of patients were higher than in the group investigated previously.

\section{Patients and Methods}

The 18 patients ( 15 men aged 21 to 66 years and three women aged 31 to 60 years) had been admitted to the Koningin Emma Kliniek at Renkum. At the time of study none of them hid had a recent bronchial infection or attack of asthma. In addition four men aged 32 to 59 years with asthmatic bronchitis were studied before the initiation of corticosteroid treatment. The 18 patients had been on prednisone treatment for periods of 13 months to 10 years at an initial dosage of $15 \mathrm{mg}$ daily, which later had been gradually decreased as far as the clinical condition permitted by steps of $2.5 \mathrm{mg}$ daily.

In all subjects the cortisol production rate was determined on the first day of the study and plasma fluorogenic corticosteroids were measured at 8.30 a.m. and 4.30 p.m. on days 2 and 3 . On the fourth day an intravenous infusion of $0.25 \mathrm{mg}$ of tetracosactrin (Synacthen) in $500 \mathrm{ml}$ of saline was given over eight hours. On this day the cortisol production rate was determined again and plasma fluorogenic corticosteroids were measured at the beginning and end of the infusion. Prednisone treatment was continued during the tests. The cortisol production rate was determined by a modification of the method of Cope and Black

University Hospital, Utrecht, Holland

L. WESTERHOF, M.D., Formerly Assistant, Department of Pulmonary Diseases

M. J. vaN DITMARS, M.D., Formerly Consultant, Department of Pulmonary Diseases

P. J. DER KINDEREN, M.D., Consultant, Department of Clincial Endo-

. H. H. THIJSSEN, PH.D., Head of Steroid Laboratory, Department of - H. H. THIJSSEN, PH.

F. SCHWARZ, M.D., Head of Department of Clinical Endocrinology
(Thijssen et al., 1967). Plasma fluorogenic corticosteroids were measured according to Mattingly (1962).

Normal values were derived for the cortisol production rate from 23 volunteers aged 20 to 45 years, for plasma fluorogenic corticosteroids from 27 volunteers aged 20 to 45 years, and for the tetracosactrin stimulation from 10 volunteers aged 28 to 59 years.

\section{Results}

In Figs. 1 to 4 the results are compared with those obtained in the previous study on sarcoidosis patients. It can be seen that

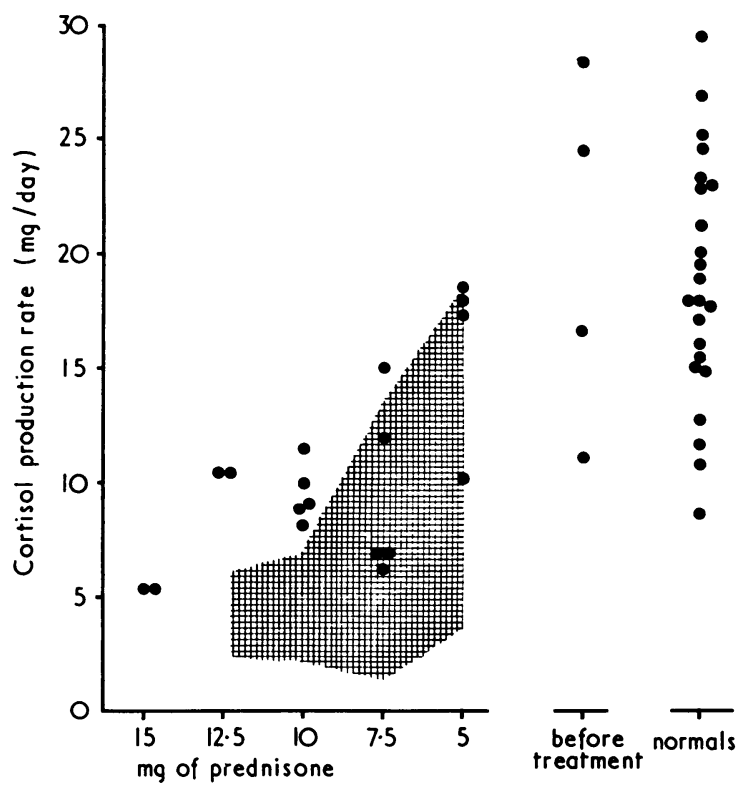

FIG. 1-Cortisol production rate in relation to dosage of prednisone. Shadowed area shows range of results in patients with sarcoidosis (Westerhof owed area show
et al., 1970).
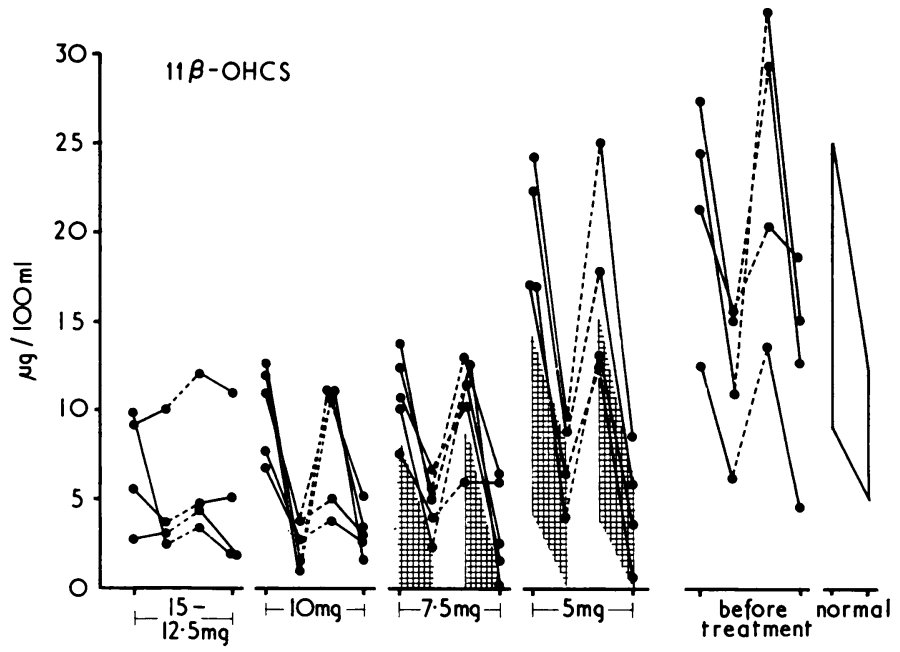

FIG. 2-Plasma fluorogenic corticosteroids (11-OHCS) at $8.30 \mathrm{a.m}$. and 4.30 p.m. on two consecutive days in relation to dosage of prednisone. Shadowed area shows range of results in patients with sarcoidosis (Westerhof et al., 1970). 


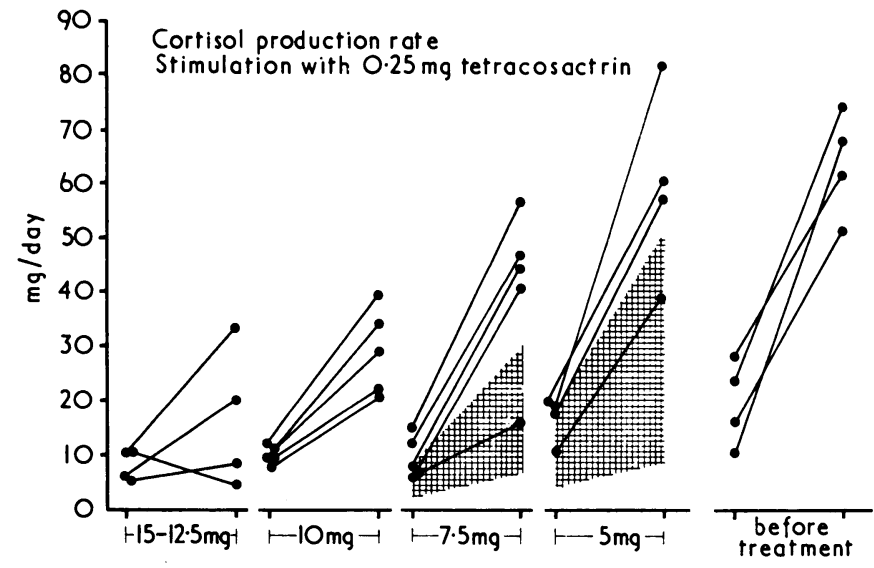

FIG. 3-Cortisol production rate determined under basal conditions and on day of a tetracosactrin infusion in relation to dosage of prednisone. Values pertaining to same patient are connected. Shadowed area shows range of results in patients with sarcoidosis (Westerhof et al., 1970)

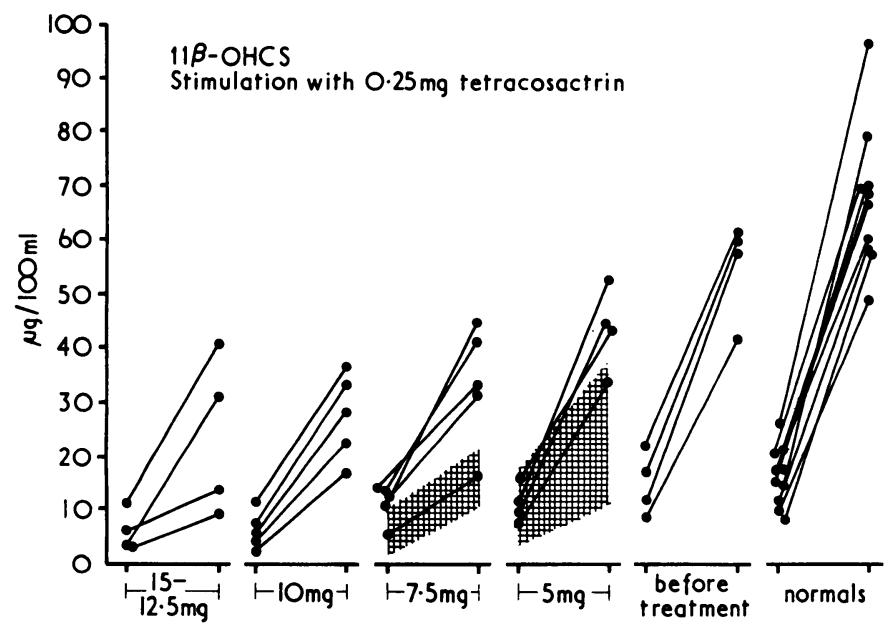

FIG. 4-Plasma fluorogenic corticosteroids before and at end of a tetracosactrin infusion in relation to dosage of prednisone. Values pertaining to same patients are connected. Shadowed area shows range of results in patients with sarcoidosis (Westerhof et al., 1970).

there was no difference between the values of the asthma patients before corticosteroid treatment and those of volunteers.

The cortisol production rate (Fig. 1) could be compared at dosage levels of 12.5 to $5 \mathrm{mg}$ of prednisone. At 12.5 and $10 \mathrm{mg}$ the values found in the asthma patients were above the range of the sarcoidosis group, and at 7.5 and $5 \mathrm{mg}$ they were above the average values of the sarcoidosis group. This difference is significant $(P<0.01)$ according to the test of Wilcoxon between the two groups at $5 \mathrm{mg}$ of prednisone.

Plasma fluorogenic corticosteroids and the response to tetracosactrin stimulation could be compared at levels of 7.5 and $5 \mathrm{mg}$. In each instance higher values were found in the asthma group. The difference in basal fluorogenic corticosteroids (Fig. 2) is significant at $P<0.01$ and the response to stimulation is significant at $P<0.05$.

\section{Discussion}

The general trend of recovery of the adrenocortical function was similar in both groups of patients. It is evident, however, that at corresponding dosages of prednisone the adrenocortical function of the patients with asthmatic bronchitis was better than that of sarcoidosis patients. Several explanations must be considered.

The disease for which these patients are treated could influence the adrenal cortex. It is conceivable that repeated attacks of asthma would stimulate the pituitary-adrenal axis, preventing adrenal atrophy during corticosteroid treatment. In this event, however, one would expect to find raised steroid values in untreated cases. Enhanced adrenocortical function has never been recorded. Van der Straeten (1964) found a decreased rate of cortisol production but Robson and Kilborn (1965) found normal values. Blumenthal et al. (1966) found normal values of plasma fluorogenic corticosteroids and a norm? nyctohemeral rhythm. In four of the present patients studied before corticosteroid treatment all values were in the normal range. There are no indications that basal adrenocortical function is altered in sarcoidosis. It is improbable that the nature of the disease is responsible for the differences found.

The sarcoidosis patients had been treated for three to six years. In the asthma patients the variation in duration of treatment was much wider. The cortisol production rate in relation to the duration of treatment of the asthma patients is shown in Fig. 5. No influence can be seen and certainly no negative correlation, which might be expected if the duration of treatment was a significant factor. The same lack of correlation for the cortisol production rate in relation to the total amount of prednisone administered is shown in Fig. 6.

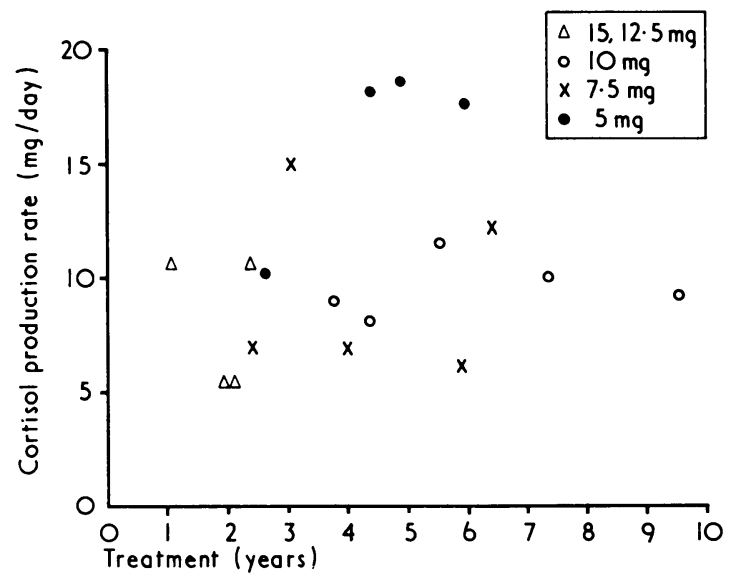

FIG. 5-Cortisol production rate in relation to duration of prednisone therapy.

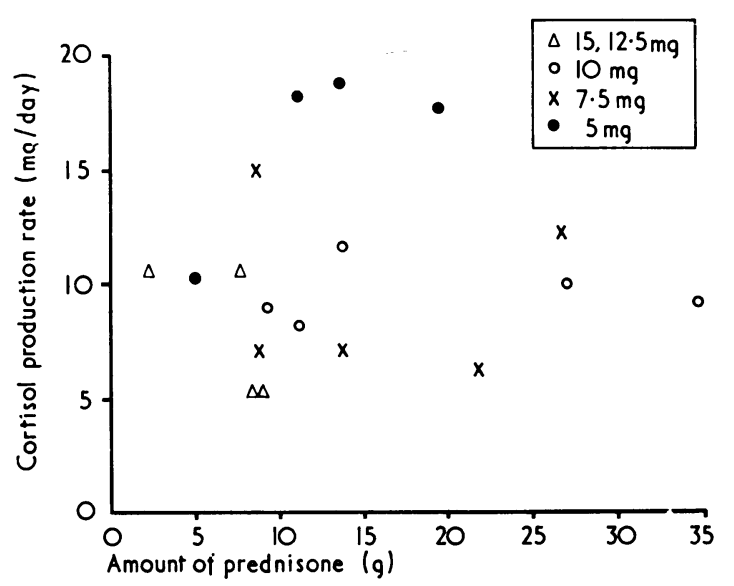

FIG. 6-Cortisol production rate in relation to total amount of prednisone administered.

Data from the literature are contradictory in this respect. Bierich et al. (1959) and Jakobson et al. (1968) found a correlation between the depression of adrenocortical function and the duration of treatment expressed as the total amount of corticosteroids given. Sandberg et al. (1957) and Daly et al. (1967) found no correlation.

In both groups of patients the prednisone was distributed over the day in the same way at levels of $12.5,10$, and $7.5 \mathrm{mg}$; $5 \mathrm{mg}$ was given to sarcoidosis patients in one morning dose and to asthma patients in two doses of $2.5 \mathrm{mg}$. As the hypothalamo- 
pituitary-adrenal axis is more susceptible to suppression in the evening than in the morning (Grant et al., 1965) this difference in treatment could not have led to the lower values found in the sarcoidosis patients.

Our results become comprehensible when it is realized that the recovery of adrenocortical function during the tapering off of corticosteroids is caused by gradual resumption of pituitary ACTH secretion. The rate at which these small amounts of ACTH are effective will depend on the degree of adrenocortical atrophy which had developed in earlier stages of treatment. If doses have been given which are much above the physiological range (in our case $40 \mathrm{mg}$ daily) endogenous ACTH stimulus might be entirely absent for some time, leading to severe atrophy and slow recovery. A smaller dosage (for example, 15 mg daily) will not lead to complete suppression of ACTH and the adrenal cortex will later be able to respond more readily to endogenous stimulation.

It is therefore probable that the difference we found between the sarcoidosis patients and the asthma patients can be explained by the difference in level of the initial dose of prednisone.

Some contradictory results from the literature could be explained by this theory. Robinson et al. (1962) found normal plasma fluorogenic corticosteroids in almost all patients one day after sudden withdrawal of corticosteroids. The patients, however, had not been so severely suppressed as those reported on by Graber et al. (1965), who found after more gradual withdrawal decreased corticosteroid and enhanced ACTH values.
Proof of our theory can be obtained by treating sarcoidosis patients during the initial $40-\mathrm{mg}$ prednisone period with small doses of corticotrophin and then waiting for the recovery of adrenocortical function in the withdrawal phase. Such an investigation has been started but as the same schedule has to be followed as in the former study it will be some years before results are available.

\section{References}

Bierich, J. R., Kersten, I., and Maruektad, S. (1959). Acta Endocrinologica (Kobenhavn), 31, 40.

Blumenthal, M. N., McLean, J. A., Mathews, K. P., and Sheldon, J. M. (1966). Archives of Internal Medicine, 117, 34.

Daly, J. R., Myles, A. B., Bacon, P. A., Beardwall, C. G., and Savage, O. (1967). Annals of the Rheumatic Diseases, 26, 18.

Graber, A. L., Ney, R. L., Nicholson, W. E., Island, D. P., and Liddle, G. W. (1965). Fournal of Clinical Endocrinology and Metabolism, 25, 11.

Grant, S. D. Forshman, P. H., and Di Raimondo, V. D. (1965). New England fournal of Medicine, 273, 1115.

Jakobson, T., Sundberg, M., Kotovirta, M., and Strandström, L. (1968). Acta Endocrinologica (Kobenhavn), 59, 76

Mattingly, D. (1962). Fournal of Clinical Pathology, 15, 374

Robinson, B. H. B., Mattingly, D., and Cope, C. L. (1962). British Medical fournal, 1, 1579.

Robson, A. O., and Kilborn, J. R. (1965). Thorax, 20, 93.

Sandberg, A. R., Eik-Nes, K., Migeon, C. J., and Koepf, G. F. (1957). Fournal of Laboratory and Clinical Medicine, 50, 286.

Straeten, M. van der (1964). Thesis, Ghent.

Thijssen, J. H. H., Waard, F. de, and Wiersinga, A. (1967). Lancet, 1, 814.

Westerhof, L., Ditmars, M. J. van, Kinderen, P. J. der, Thijssen, J. H. H. and Schwarz, F. (1970). British Medical fournal, 4, 534.

\title{
Diphtheria-Tetanus-Pertussis Immunization by Intradermal Jet Injection
}

\author{
J. P. STANFIELD, P. M. BRACKEN, K. M. WADDELL， D. GALL
}

British Medical fournal, 1972, 2, 197-199

\section{Summary}

An intradermal jet injector was used to administer combined diphtheria, tetanus, and pertussis (D.T.P.) vaccines to infants aged 2 to 12 months. A second dose was given one month after the first and a third six months after the second. Each dose was considerably smaller than the standard intramuscular dose. Blood samples taken one month after the third dose showed a satisfactory diphtheria and tetanus antitoxin response in all but a few cases. The antibody response to the pertussis component was not examined. Reactions were insignificant. Intradermal jet injection is proposed as a cheap, extremely rapid, and effective technique for D.T.P. immunization, especially suitable for use in remote areas where trained staff and facilities are few and many children require immunization.

Makerere University Medical School, Kampala, Uganda J. P. STANFIELD, M.D., M.R.C.P., Professor of Paediatrics and Child

P. M. BRACKEN, F.I.M.L.T., Senior Technician

Kagando Hospital, Africa Inland Mission, Uganda

K. M. WADDELL, M.B., CH.B., M.R.C.P., Medical Officer in Charge

Wellcome Research Laboratories, Beckenham, Kent

D. GALL, B.M., B.CH., D.T.M.\&H., Immunologist, Department of Aerobic Bacteriology.

\section{Introduction}

The use of the intradermal jet injector makes it possible to carry out immunization on a mass scale with the minimum of trained staff and facilities. The unreliability of some of the early models has been overcome and the instrument remains relatively cheap (about $£ 25$ ). It has been used successfully for the administration of B.C.G. vaccine (Moffat and Cook, 1970), smallpox vaccine (Heyworth, 1970), and tetanus toxoid (Rey and Triau, 1967), though recently reservations have been expressed about its use for measles immunization (S. Dauchy, personal communication, 1969; Stanfield and Bracken, 1971).

In most countries combined diphtheria, tetanus, and pertussis (D.T.P.) vaccine is now included in comprehensive immunization schedules together with poliomyelitis, B.C.G., and smallpox vaccines. The usual route of administration of D.T.P. is intramuscular, but in a controlled trial reported by Dick (1966) infants given one-third of the standard dosage of quadruple (D.T.P. + polio) vaccine by intradermal (needle) injection developed antibody levels similar to those produced by the full dosage injected intramuscularly. No constitutional upset or severe local reactions were observed. It was therefore decided to study the efficacy of D.T.P. immunization by intradermal jet injection in the field.

\section{Patients and Methods}

The trial was carried out at Kagando Hospital, with 70 beds in the care of a single doctor, situated in an isolated but heavily populated area of West Uganda. Between 1,000 and 1,500 